\title{
A pitfall in the diagnosis of child abuse: external hydrocephalus, subdural hematoma, and retinal hemorrhages
}

\section{Joseph H. Piatt, Jr, M.D.}

Departments of Neurosurgery and Pediatrics. Oregon Health Sciences University, Portland, Oregon

External hydrocephalus has been associated with subdural hematomas in infancy, and the hematomas have been noted to be secondary to minor trauma or have even been described as spontaneous. The author reports the case of an infant with external hydrocephalus who developed retinal as well as subdural hemorrhages after sustaining a minor head injury. Although retinal hemorrhage in infancy has been considered virtually pathognomonic of child abuse, in the setting of external hydrocephalus a more cautious interpretation may be appropriate.

Key Words * child abuse * craniocerebral disproportion * external hydrocephalus * retinal hemorrhage * subdural hematoma

One clinical hallmarks of child abuse is a discrepancy between the traumatic lesion that the patient exhibits and the causative explanation offered by the caretaker.[19] The explanation may appear to be discrepant on a developmental basis: the child, for example, is reported to have caused a self injury that is inconsistent with his developemental level. Or the discrepancy may be a mechanistic one: the severity of the injury is out of proportion with the forces purportedly involved in the accident. In the latter case, the physician must exercise diligence to rule out preexisting diseases, such as platelet disorders, deficiencies of coagulation factors, and osteogenesis imperfecta, that might render the child exceptionally susceptible to injury.[8,11,17,32]

External hydrocephalus is a common condition characterized by diffuse enlargement of the subarachnoid spaces.[2,3,5,6,10,16,21,23,24,29,31,36,38,40,41] It is most often associated with macrocephaly, but there are children with normal or even small head circumferences in whom diffuse enlargement of the subarachnoid spaces has developed.[1,5,33] The description, "benign subdural effusions of infancy," was used to characterize this condition before the era of modern neuroimaging, $[7,25,39]$ but it is a misnomer because the excessive fluid resides in the subarachnoid space rather than in the subdural space. $[4,44]$ In many instances a family history consistent with a dominant pattern of inheritance can be elicited. The natural history is generally benign, and there are normal developmental outcomes in most cases as well as imaging-documented resolution of abnormalities by the time the patient reaches school age.

Whereas enlargement of the subarachnoid spaces persists during infancy, the brain does not fill the space 
available within the cranial cavity, and a state of "craniocerebral disproportion" exists. The presence of craniocerebral disproportion that develops from any cause--external hydrocephalus, internal hydrocephalus, arachnoid cyst, or chronic subdural hematoma--makes the patient exceptionally susceptible to subdural hemorrhage after what would otherwise be inconsequential trauma.[5,14,18,21,26,30,35,37] In particular, the prevalence of subdural hematoma in case series of patients with external hydrocephalus seems significant. In a study reported by Azais and Echenne,[5] "spontaneous" subdural hemorrhage was demonstrated in five of 41 patients with "benign enlargement of the subarachnoid spaces" on ultrasonography and computerized tomography scanning. Laubscher, et al.,[21] have described a "nonbattered" infant among their 22 patients with pericerebral subarachnoid space enlargement, in whom a "spontaneous" subdural "hygroma" developed that the authors attributed to the vulnerability of the bridging subarachnoid veins. Mori, et al.,[26] have reported three infants with subdural hemorrhage of 20 patients with infantile subarachnoid fluid collection. Although they fall within the shadow of publication bias, these series suggest that the prevalence of subdural hematoma in infants with external hydrocephalus may be as high as $11 \%$.

Caffey,[9] who first described the shaken infant syndrome, recognized that infants with hydrocephalus were prone to the development of subdural hematomas, but neither he nor any subsequent author has arrived at the following logical conclusion: the development of a subdural hematoma after minor trauma in an infant with craniocerebral disproportion might be the occasion for unjustified accusations of child abuse. The concomitant presence of retinal hemorrhages in such an instance would reinforce that the diagnosis of inflicted injury is incorrect in such cases.

\section{CASE REPORT}

History. Emergency medical technicians were called to evaluate this 4-month-old boy because of status epilepticus.

Presentation. The child had been well except for the presence of macrocephaly. At 6 weeks of age his head circumference had been measured as $41.5 \mathrm{~cm}$ (>95th percentile). On the day of presentation, his mother had been propping him up in a standing position against a piece of furniture in the presence of his father and paternal grandmother. The mother became distracted, and the infant fell, striking the back of his head on a carpeted floor. He cried immediately, but soon experienced a generalized convulsion. A sequence of generalized convulsions followed and ceased only after diazepam was administered rectally.

Examination. General physical assessment at the receiving hospital revealed no other injuries. The patient's head circumference measured $44.3 \mathrm{~cm}$ ( $>95$ th percentile). Funduscopic examination demonstrated retinal, preretinal, and subhyaloid hemorrhages (Fig. 1). 


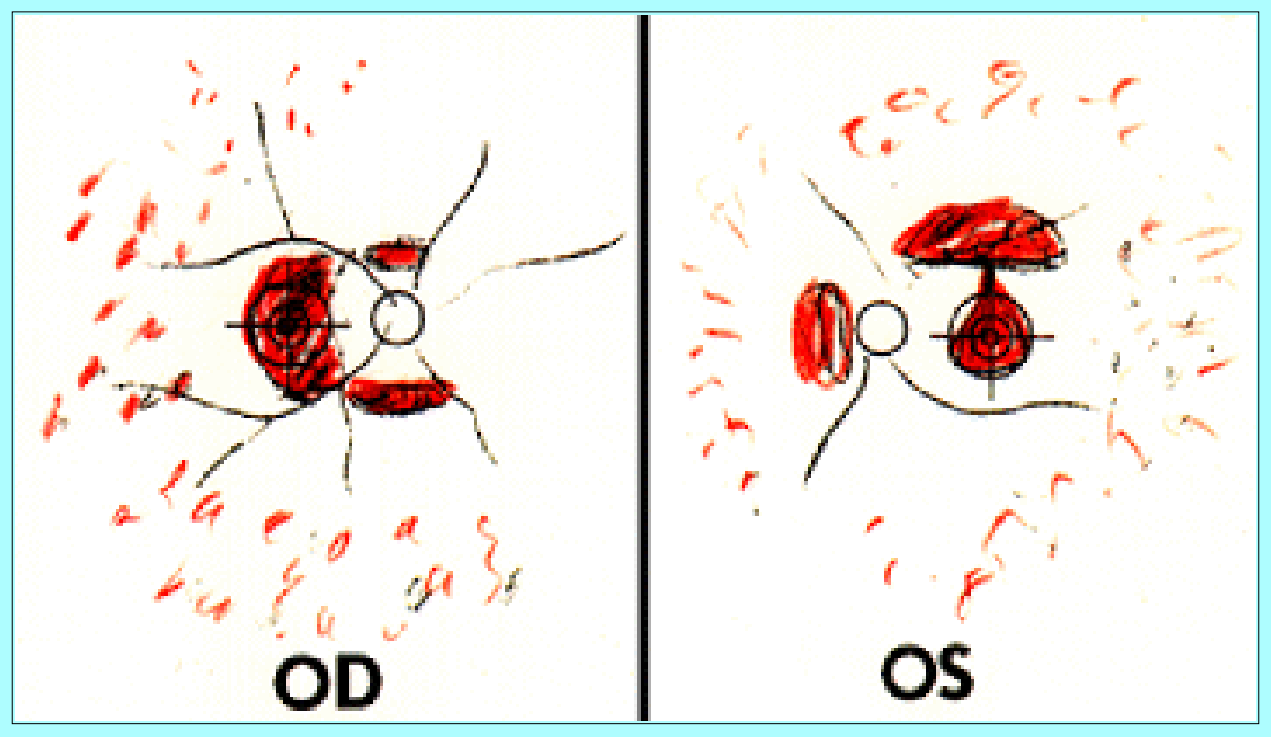

Fig. 1. Fundus drawings demonstrating extensive, deep blot hemorrhages in all four quadrants of both eyes. In this case report there were preretinal and subhyaloid hemorrhages in each eye as well. Both optic nerve heads were well perfused and had sharp margins. There were no abnormalities of the nerve fiber layer. (Drawings courtesy of William Rodden, M.D., Ashland, Oregon).

A computerized tomography scan of the head revealed a small acute subdural hematoma that was associated with bilateral low-density extracerebral fluid collections. On Day 3 postadmission magnetic resonance imaging established that these fluid collections reflected diffuse enlargement of the subarachnoid spaces (Fig. 2). A skeletal survey was negative.
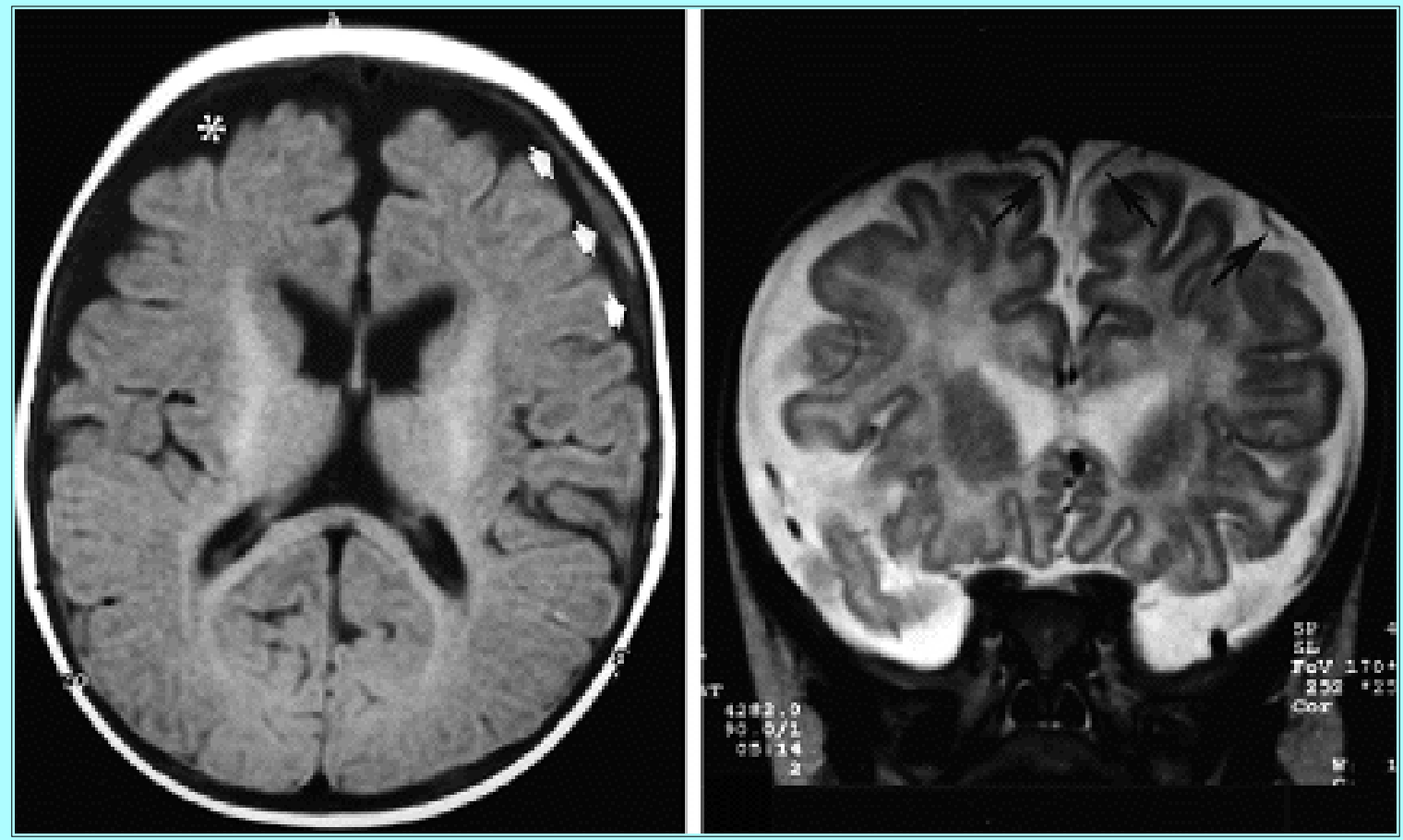

Fig. 2. Magnetic resonance imaging studies. Upper: A transaxial, $T_{1}$-weighted image of the head demonstrating a small left frontal subdural hematoma of mixed intensities (white arrow heads). There is a prominent, symmetrical, extracerebral fluid collection of the same intensity as ventricular cerebrospinal fluid (CSF) (white asterisk). Lower: Coronal, $\mathrm{T}_{2}$-weighted image demomstrating that the extracerebral fluid remains at the same intensity 
as ventricular CSF, and anastomotic veins can be seen passing from the surface of the cortex to the dura through it (black arrows). The extracerebral fluid therefore represents enlargement of the subarachnoid space. These images are diagnostic of external hydrocephalus.

The patient recovered without specific treatment.

Investigation of Physical Abuse. An extensive police and social service investigation, which at the parents' request included polygraph testing, failed to uncover any risk factors or circumstances suspicious for child abuse.

Diagnosis. The infant was seen in pediatric neurosurgical consultation at age 6 months, at which time he was well. The only notable physical finding was a head circumference that measured $47 \mathrm{~cm}$. The diagnosis of external hydrocephalus was made at this time.

Follow-Up Course. Under careful ophthalmological surveillance, the retinal hemorrhages were noted to clear within 3 months, and the subhyaloid hemorrhages cleared within 6 months. No amblyopia or other visual disturbance persisted.

The patient remained at his home in the care of his natural parents, and at his 18 month follow-up examination, his development was normal. His head circumference measured $51 \mathrm{~cm}$. Magnetic resonance imaging of his head showed very mild prominence of the subarachnoid spaces and judged to be within normal limits. A telephone follow-up interview with the community physician of the patient when he was 44 months of age indicated excellent general health, perfectly normal development, and a stable family life.

\section{DISCUSSION}

The coexistence of subdural hematoma and retinal hemorrhage in an infant is considered virtually indicative that child abuse has occurred. The significance of these findings has been established over time by their frequent association with other typical signs of abuse: injuries at various ages and those affecting various body parts, as well as parental delay in seeking medical attention. In the case described here, however, no other injuries or suspicious circumstances were present, and the accusations of abuse grew entirely out of the perception that the mechanism of the injury was implausible. Although the question of inflicted injury can never be dismissed completely, the recognition of preexisting external hydrocephalus in this case at least partly undermines the explanation that the subdural hematomas were mechanistically implausible. Furthermore, the small volume of the hematomas and the absence of lasting neurological sequelae constitute additional evidence that the traumatic forces responsible for the injury case were not great. The child's subsequent healthy development in his home environment further validates the diagnosis that his injury was accidental.

The mechanism for the development of subdural hemorrhage in infants has been thought to be shear injury to the anastomotic veins, passing from the surface of the cerebral cortex to the dural venous sinuses, particularly the sagittal sinus.[12] Because the brain and the skull have differing viscoelastic properties, sudden forces applied to the head cause the brain to "slosh" inside the skull.[34] Regardless of cause, craniocerebral disproportion compromises the natural mechanical stability of the brain within the skull. In cases in which external hydrocephalus is present, the bridging veins passing from the cerebral convexities to the dural venous sinuses may be rendered more vulnerable to shear injury by their long courses through the exaggerated subarachnoid spaces. 
The association of retinal hemorrhage with catastrophic intracranial hemorrhage is familiar to all neurosurgeons. Aneurysmal subarachnoid hemorrhage is the paradigm, and the accepted mechanism is transmission of the sudden elevation of intracranial pressure to the central retinal vein and its choroidal anastomoses via the subarachnoid space of the optic nerve sheaths.[20,27] In infancy retinal hemorrhages have long been recognized as a distinctive feature of head injury caused by physical abuse, $[13,28,42]$ but the physical mechanisms remain to be clarified.[15] One possibility is that the rupture of retinal veins is caused by a pressure surge transmitted either from the cranial cavity through the subarachnoid space of the optic nerve sheaths or from the chest through the cervicocephalic veins (the so-called Purtscher retinopathy).[42] Another possibility, by analogy with subdural hemorrhage, is that a direct acceleration-deceleration insult to the globe causes shear stresses between the ocular tissues with differing mechanical properties; this mechanism of injury is especially prominent in autopsy cases.[15,22] Because a gradation of inflicted ocular injury corresponds to the gradation of severity of the associated intracranial injury, $[15,43]$ different mechanisms likely come into play in response to varying degrees of violence.

To the best of the author's knowledge, retinal hemorrhages have not been described before in association with minor trauma in the setting of external hydrocephalus. Whether or not external hydrocephalus imparts a special susceptibility to ocular hemorrhage is unknown; however, in the present case the involvement of the eyes seems severe in relation to the extent of the intracranial hemorrhage. One mechanistic hypothesis is that the subarachnoid spaces along the optic nerves may be dilated in the same manner as the intracranial subarachnoid spaces are. Furthermore, the dilated intracranial subarachnoid spaces may transmit pressure impulses more efficiently, and with less dampening than in the normal state. Intracranial compliance may be low in the setting of external hydrocephalus as well. A minor skull impact could therefore generate an exaggerated intracranial pressure impulse that might, in turn, be transmitted undampened out along the optic nerves and into the orbits as far as the globes. Because of the format of the imaging studies obtained in the case reported here, it was not possible to assess the subarachnoid spaces within the optic nerve sheaths, and so this explanation remains speculative.

Until its pathogenesis has been elucidated more thoroughly, the forensic interpretation of retinal hemorrhage should be handled cautiously in the setting of external hydrocephalus. In many familiar clinical situations, retinal hemorrhage is linked to the occurrence of sudden pressure transients within the cranial cavity. The mechanical properties of the cranium and its contents are abnormal in cases of external hydrocephalus, and the mechanical coupling of the cranium and eye may therefore be abnormal as well. The outcome of the case reported here reinforces this line of reasoning and raises a concern that can only be settled by additional clinical experience and, perhaps, experimental data: in the setting of external hydrocephalus, retinal hemorrhage may not be pathognomonic of abusive injury.

\section{References}

1. Akaboshi I, Ikeda T, Yoshioka S: Benign external hydrocephalus in a boy with autosomal dominant microcephaly. Clin Genet 49:160-162, 1996

2. Alvarez LA, Maytal J, Shinnar S: Idiopathic external hydrocephalus: natural history and relationship to benign familial macrocephaly. Pediatrics 77:901-907, 1986

3. Andersson H, Elfverson J, Svendsen P: External hydrocephalus in infants. Childs Brain 11:398-402, 1984 
4. Aoki N: Extracerebral fluid collections in infancy: role of magnetic resonance imaging in differentiation between subdural effusion and subarachnoid space enlargement. J Neurosurg 81:20-23, 1994

5. Azais M, Echenne B: [Idiopathic pericerebral swelling (external hydrocephalus) of infants.] Ann Pediatr 39:550-558, 1992 (Fr)

6. Bode H, Strassburg HM: [Craniocerebral dysproportion--a contribution to the significance of extracerebral fluid collections in infancy.] Klin Padiatr 199:399-402, 1987 (Ger)

7. Briner S, Bodensteiner J: Benign subdural collections of infancy. Pediatrics 67:802-804, 1981

8. Brown JK, Minns RA: Non-accidental head injury, with particular reference to whiplash shaking injury and medico-legal aspects. Dev Med Child Neurol 35:849-869, 1993

9. Caffey J: On the theory and practice of shaking infants. Its potential residual effects of permanent brain damage and mental retardation. Am J Dis Child 124:161-169, 1972

10. Carolan PL, McLaurin RL, Towbin RB, et al: Benign extra-axial collections of infancy. Pediatr Neurosci 12:140-144, 1985

11. Dietrich AM, James CD, King DR, et al: Head trauma in children with congenital coagulation disorders. J Pediatr Surg 29:28-32, 1994

12. Duhaime AC, Gennarelli TA, Thibault LE, et al: The shaken baby syndrome. A clinical, pathological, and biomechanical study. J Neurosurg 66:409-415, 1987

13. Gilkes MJ, Mann TP: Fundi of battered babies. Lancet 2:468-469, 1967

14. Gout A, Gautier I, Bellaiche M, et al: [Idiopathic peri-cerebral enlargement in infants: simple anatomical variant or hemorrhagic risk factor?] Arch Pediatr 4:983-987, 1997 (Fr)

15. Green MA, Lieberman G, Milroy CM, et al: Ocular and cerebral trauma in non-accidental injury in infancy: underlying mechanisms and implications for paediatric practice. Br J Ophthalmol 80:282-287, 1996

16. Hamza M, Bodensteiner JB, Noorani PA, et al: Benign extracerebral fluid collections: a cause of macrocrania in infancy. Pediatr Neurol 3:218-221, 1987

17. Hymel KP, Abshire TC, Luckey DW, et al: Coagulopathy in pediatric abusive head trauma.

Pediatrics 99:371-375, 1997

18. Kapila A, Trice J, Spies WG, et al: Enlarged cerebrospinal fluid spaces in infants with subdural hematomas. Radiology 142:669-672, 1982

19. Kempe CH: Paediatric implications of the battered baby syndrome. Arch Dis Child 46:28-37, 1971

20. Khan SG, Frenkel M: Intravitreal hemorrhage associated with rapid increase in intracranial pressure (Terson's syndrome). Am J Ophthalmol 80:37-43, 1975

21. Laubscher B, Deonna T, Uske A, et al: Primitive megalencephaly in children: natural history, medium term prognosis with special reference to external hydrocephalus. Eur J Pediatr 149:502-507, 
22. Massicotte SJ, Folberg R, Torczynski E, et al: Vitreoretinal traction and perimacular retinal folds in the eyes of deliberately traumatized children. Ophthalmology 98:1124-1127, 1991

23. Maytal J, Alvarez LA, Elkin CM, et al: External hydrocephalus: radiologic spectrum and differentiation from cerebral atrophy. AJR 148:1223-1230, 1987

24. Ment LR, Duncan CC, Geehr R: Benign enlargement of the subarachnoid spaces in the infant. J Neurosurg 54:504-508, 1981

25. Mori K, Handa H, Itoh M, et al: Benign subdural effusion in infants. J Comput Assist Tomogr 4:466-471, 1980

26. Mori K, Sakamoto T, Nishimura K, et al: Subarachnoid fluid collection in infants complicated by subdural hematoma. Childs Nerv Syst 9:282-284, 1993

27. Muller PJ, Deck JHN: Intraocular and optic nerve sheath hemorrhage in cases of sudden intracranial hypertension. J Neurosurg 41:160-166, 1974

28. Mushin A, Morgan G: Ocular damage in the battered-baby syndrome. Report of two cases. Br J Ophthalmol 55:343-347, 1971

29. Nickel RE, Gallenstein JS: Developmental prognosis for infants with benign enlargement of the subarachnoid spaces. Dev Med Child Neurol 29:181-186, 1987

30. Nishimura K, Mori K, Sakamoto T, et al: Management of subarachnoid fluid collection in infants based on a long-term follow-up study. Acta Neurochir 138:179-184, 1996

31. Nogueira GJ, Zaglul HF: Hypodense extracerebral images on computed tomography in children. "External hydrocephalus": a misnomer? Childs Nerv Syst 7:336-341, 1991

32. O'Hare AE, Eden OB: Bleeding disorders and non-accidental injury. Arch Dis Child 59:860-864, 1984

33. Odita JC: The widened frontal subarachnoid space. A CT comparative study between macrocephalic, microcephalic, and normocephalic infants and children. Childs Nerv Syst 8:36-39, 1992

34. Ommaya AK, Faas F, Yarnell P: Whiplash injury and brain damage: an experimental study. JAMA 204:285-289, 1968

35. Page AC, Mohan D, Paxton RM: Arachnoid cysts of the middle fossa predispose to subdural haematoma formation fact or fiction? Acta Neurochir Suppl 42:210-215, 1988

36. Palencia Luaces R, Aldana Gómez J, Tresierra Unzaga F: [Idiopathic external hydrocephaly and familial macrocephaly in infancy.] An Esp Pediatr 36:186-188, 1992 (Sp)

37. Parsch CS, Krauss J, Hofmann E, et al: Arachnoid cysts associated with subdural hematomas and hygromas: analysis of 16 cases, long-term follow-up, and review of the literature. Neurosurgery 40:483-490, 1997

38. Pettit RE, Kilroy AW, Allen JH: Macrocephaly with head growth parallel to normal growth pattern: 
neurological, developmental, and computerized tomography findings in full-term infants. Arch Neurol 37:518-521, 1980

39. Robertson WC Jr., Chun RW, Orrison WW, et al: Benign subdural collections of infancy. J Pediatr 94:382-386, 1979

40. Roshan K, Elizabeth C, Chacko A, et al: External hydrocephalus--a report of 16 cases from Oman. J Trop Pediatr 44:153-156, 1998

41. Shen WC, Yang CF, Chang T: Benign hydrocephalus in infants. A computed tomographic and clinical correlative study. Acta Radiol Suppl 369:689-691, 1986

42. Tomasi LG, Rosman NP: Purtscher retinopathy in the battered child syndrome. Am J Dis Child 129:1335-1337, 1975

43. Wilkinson WS, Han DP, Rappley MD, et al: Retinal hemorrhage predicts neurologic injury in the shaken baby syndrome. Arch Ophthalmol 107:1472-1474, 1989

44. Wilms G, Vanderschueren G, Demaerel PH, et al: CT and MR in infants with pericerebral collections and macrocephaly: benign enlargement of the subarachnoid spaces versus subdural collections. AJNR 14:855-860, 1993

Manuscript received July 12, 1999.

Accepted in final form August 31, 1999.

Address reprint requests to: Joseph Piatt, M.D., Department of Neurosurgery (L472), Oregon Health Sciences University, Portland, Oregon 97201-3098. email: piattj@ohsu.edu. 